\title{
COMPARATIVE EVALUATION OF TENSILE BOND STRENGTH OF NICKEL-CHROMIUM ALLOY TO DENTAL ENAMEL USING DIFFERENT RESIN CEMENTS - AN IN VITRO STUDY.
}

\author{
Deepika $^{1}$, Manjit Kumar ${ }^{2}$, Abhishek Gupta ${ }^{3}$, Vandana Chabhra ${ }^{4}$ \\ ${ }^{1}$ Senior lecturer Sukhmani Dental College and Hospital, Punjab, India \\ ${ }^{2}$ Professor and Head, Department of Prosthodontics, Bhojia Dental College and Hospital, Himachal Pradesh, India \\ ${ }^{3}$ Reader, MGS Dental College, Rajasthan, India \\ ${ }^{4}$ Reader, HS Judge Dental College, Chandigarh, India
}

Corresponding Author:

Deepika

E-mail:

drdeepikakamboj@gmail.com Received: $12^{\text {th }}$ September 2016

Accepted: $2^{\text {nd }}$ December 2016

Online: $20^{\text {th }}$ January 2017

\begin{abstract}
Aim: The aim of this study was to evaluate and compare the tensile bond strength of nickel-chromium alloy to dental enamel by using four different resin cements. Materials and Methods: 40 extracted central incisor teeth embedded in acrylic blocks were flattened not to expose dentin. Wax rectangular blocks of $5 \mathrm{~mm}$ length, $5 \mathrm{~mm}$ width and $1 \mathrm{~mm}$ height with a loop were invested and casted using Nickel-Chromium alloy by conventional induction casting method and sandblasted. Then casted rectangular blocks and 40 tooth embedded acrylic samples were divided into four groups (10 each) and cemented to tooth enamel following manufacturer's instructions as; Group A cemented using RelyX U200, Group B cemented using Smartcem 2, Group C cemented using Multilink Speed and Group D cemented using Multilink N and then stored in artificial saliva for 24 hours. The direct pull tensile test was carried out on Universal Testing Machine at cross head speed of $0.5 \mathrm{~mm} / \mathrm{min}$. Results: One way ANOVA showed a highly statistically significant $(\mathrm{p}<.01)$ difference between all the four resin cements. Post Hoc Tests- Multiple comparisons showed highly statistically significant $(\mathrm{p}<0.01)$ difference between RelyX U200: Multilink N, Smartcem 2: Multilink Speed, Smartcem 2: Multilink N, Multilink Speed: Multilink N. Difference between RelyX U200 : Smartcem 2 and RelyX U200 : Multilink Speed was statistically significant $(\mathrm{p}<0.05)$. Conclusion: Self etch resin cement (Multilink N) showed maximum mean tensile bond strength as compared to self-adhesive resin cements (Smartcem 2, RelyX U200 and Multilink Speed). Clinically the greatest advantage of self-adhesive cements is the easy and fast application technique. But this time saving technique is not as effective as selfetch resin luting agents. The presumed benefit of saving time with self-adhesive luting agents may only be realized at the expense of compromising bond strength.
\end{abstract}

Keywords: Resin Cements, Tensile Bond Strength, Enamel, Base Metal Alloy

\section{INTRODUCTION}

The cast metal resin bonded fixed partial denture is a prosthesis that is luted to tooth structures primarily enamel where sound abutment teeth exist and only one or two teeth are missing. Various advantages of resin bonded fixed partial denture are minimal enamel reduction, no need for analgesia, simplified soft tissue management and reversible procedure. However, the longevity of indirect restorations is directly related to the adhesive effectiveness between dental tissues and resin cements. Therefore, a durable bond at the tooth restoration interface is fundamental for long-term success of an adhesive restoration.

Until recently, resin cements were divided into two subgroups according to the adhesive system used to prepare the tooth prior to cementation. One group utilizes etch and rinse adhesive systems while in the other group, enamel and dentin are prepared using self-etching primers. Self-adhesive cements which do not require any pretreatment of the tooth surface were introduced in 2002 as a new subgroup of resin cements. ${ }^{1}$

Therefore, depending on the treatment of dental tissues, resin cements 
can be classified as total-etch, self-etch, and selfadhesive resin cements. Total etch resin cement requires the use of phosphoric acid followed by multi or 2-step total-etch adhesive before the application of the resin cement. Self-etch resin cements use an acidic primer, which is not rinsed away, to modify the dental tissue surfaces before bonding. Self-adhesive resin cements are able to bond to dental tissues without previous application of a bonding adhesive.

There is a growing interest in the use of selfadhesive resin cements. The simplification in handling achieved with these new agents is expected to make the luting procedure less technique and operator sensitive. $^{2,3}$

However, there are conflicting reports regarding the enamel bond strengths of indirect restorations using these newly developed cements. Although investigators have reported a comparison of the bond strength of resin cements with various cast alloys and ceramics, the comparison of tensile bond strength of base metal alloy to dental enamel using different resin cements and comparison between self-etch and selfadhesive a new group of resin cements is still nuclear. Thus, the purpose of this study was to evaluate tensile bond strength of nickel-chromium alloy to dental enamel using different resin cements.

\section{MATERIALS AND METHODS}

40 non carious, unrestored, extracted human central incisors of comparable crown sizes were collected. Crowns along with $5 \mathrm{~mm}$ of root was retained in each tooth and grooves of $1-2 \mathrm{~mm}$ depth were made in radicular part of the teeth to aid in the retention to the acrylic in which it was to be embedded. After pouring auto polymerizing acrylic resin in the stainless steel mould teeth were placed in the centre of the mould with their buccal surfaces exposed 1-2 mm above the acrylic level. Buccal surfaces of teeth were flattened so as not to expose dentin using tooth preparation diamonds. Teeth were stored in distilled water at room temperature except at the time of tooth preparation, while embedding in acrylic blocks and impression making till cementation.

Impression of each individual sample was made in a custom tray, using medium body impression material (Aquasil, Dentsply Int.USA). Impression was poured with die stone (Kalabhai Karson Pvt. Ltd., Mumbai, India). Another stainless steel mold (5 mm length, 5 $\mathrm{mm}$ width and $1 \mathrm{~mm}$ height) was placed over lubricated dies to fabricate rectangular wax blocks. A loop was attached to the centre of wax block, which will serve as attachment to be connected to the universal testing machine, later on. An identification marking was made by adding a drop of wax towards the cervical side of the loop, which will act as a guide while cementation. The patterns were invested and casting was done using Ni$\mathrm{Cr}$ alloy (Bego, Bremen, Germany) in conventional induction casting machine (Fornax-T Bego, Bremen, Germany) and sandblasted using $50 \mu \mathrm{m}$ aluminium oxide for 15 seconds at a distance of approximately $10 \mathrm{~mm}$ with 60 psi of air pressure and cleaned in tap water in an ultrasonic cleaner for 2 minutes. The 40 tooth embedded acrylic samples with casted rectangular blocks (Figure 1 and Figure 2) were

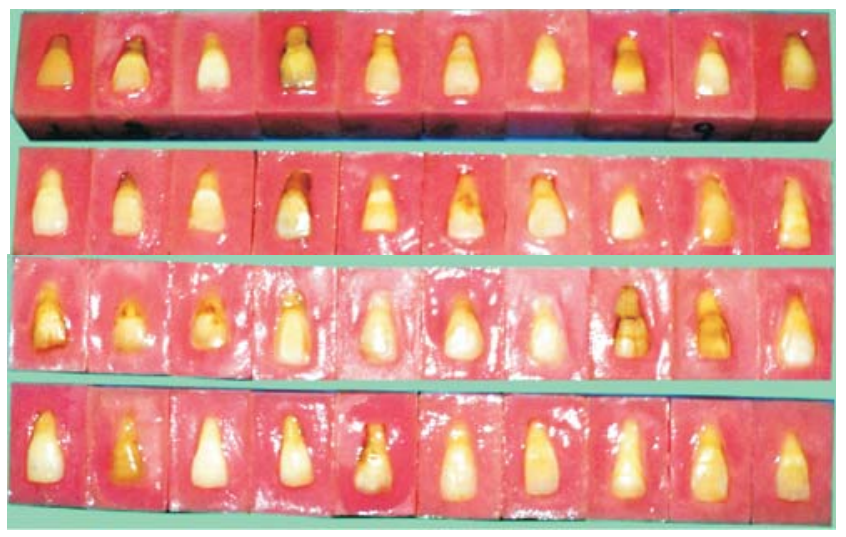

Figure 1

randomly distributed into four groups with 10 samples in each group and cemented to tooth e $\mathrm{n}$ a m e 1 fo 11 o w i n g manufacturer's instructions (Figure 3) as; Group A cemented using RelyX U200, Group B cemented using Smartcem 2, Group C cemented using Multilink Speed and

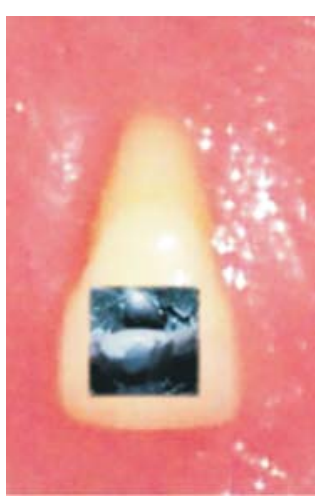

Figure 2 


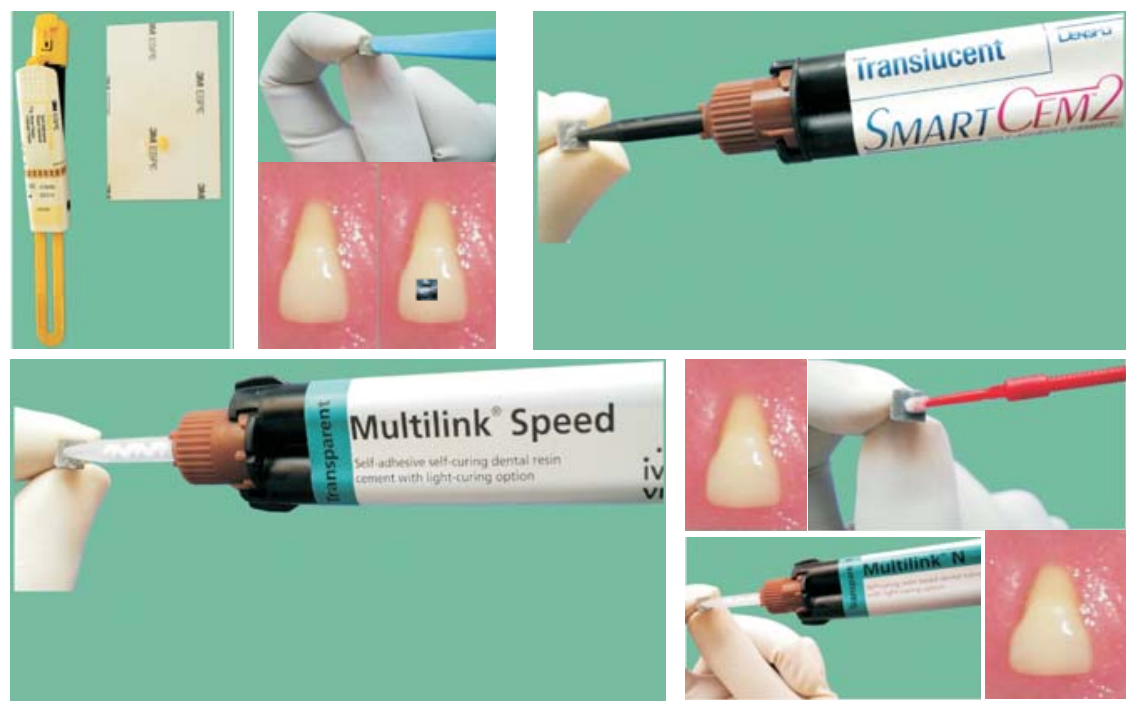

Figure 3

Table 1: Mean and standard deviation of tensile bond strength (MPa) of base metal alloy to dental enamel using four different resin cements

\begin{tabular}{|l|l|l|l|l|l|l|}
\hline Group & $\mathbf{N}$ & $\begin{array}{l}\text { Mean } \\
(\mathrm{MPa})\end{array}$ & SD & SE & Minimum & Maximum \\
\hline A & 10 & 4.5910 & .38714 & .12242 & 4.08 & 5.03 \\
\hline B & 10 & 5.0470 & .14675 & .04641 & 4.82 & 5.27 \\
\hline C & 10 & 4.1430 & .32527 & .10286 & 3.64 & 4.64 \\
\hline D & 10 & 9.2530 & .30558 & .09663 & 8.72 & 9.73 \\
\hline
\end{tabular}

Table 2: Analysis of variance (ANOVA) test for tensile bond strength $(\mathrm{MPa})$ of base metal alloy to dental enamel using four different resin cements

\begin{tabular}{|l|c|l|l|l|l|l|}
\hline & $\begin{array}{c}\text { Sum of } \\
\text { Squares }\end{array}$ & df & $\begin{array}{l}\text { Mean } \\
\text { Square }\end{array}$ & F & p value & Remarks \\
\hline $\begin{array}{l}\text { Between } \\
\text { groups }\end{array}$ & 166.907 & 3 & 55.636 & 600.506 & $<.001$ & HS \\
\hline $\begin{array}{l}\text { Within } \\
\text { groups }\end{array}$ & 3.335 & 36 & .093 & & & \\
\hline Total & 170.242 & 39 & & & & \\
\hline
\end{tabular}

Table 3: Post Hoc Tests- Multiple comparisons for tensile bond strength (MPa) of base metal alloy to dental enamel using four different resin cements

\begin{tabular}{|l|c|c|c|c|c|c|}
\hline GROUP & MD & SE & \multicolumn{2}{|l|}{$95 \%$ Confidence Interval } & \multirow{2}{*}{ p value } & \multirow{2}{*}{ Remarks } \\
\cline { 4 - 6 } & & & Lower Bound & Upper Bound & & \\
\hline $\mathbf{A}: \mathbf{B}$ & -.45600 & .13612 & -.8552 & -.0568 & .019 & $\mathrm{~S}$ \\
\hline $\mathbf{A}: \mathbf{C}$ & .44800 & .13612 & .0488 & .8472 & .022 & $\mathrm{~S}$ \\
\hline $\mathbf{A}: \mathbf{D}$ & -4.66200 & .13612 & -5.0612 & -4.2628 & $<.001$ & $\mathrm{HS}$ \\
\hline $\mathbf{B}: \mathbf{C}$ & .90400 & .13612 & .5048 & 1.3032 & $<.001$ & $\mathrm{HS}$ \\
\hline $\mathbf{B}: \mathbf{D}$ & -4.20600 & .13612 & -4.6052 & -3.8068 & $<.001$ & HS \\
\hline $\mathbf{C}: \mathbf{D}$ & -5.11000 & .13612 & -5.5092 & -4.7108 & $<.001$ & HS \\
\hline
\end{tabular}

Group D cemented using Multilink N. After half an hour all the samples were stored in artificial saliva for 24 hours.

The direct pull tensile test was carried out by passing a stainless steel wire through the loop on the cast rectangular block on Universal Testing Machine (Model no. AG IS Shimadu, Japan) (Figure 4) to determine the tensile bond strength. The cross head speed was maintained at $0.5 \mathrm{~mm} / \mathrm{min}$. The ultimate strength was noted and tensile bond strength in $\mathrm{MPa}$ 


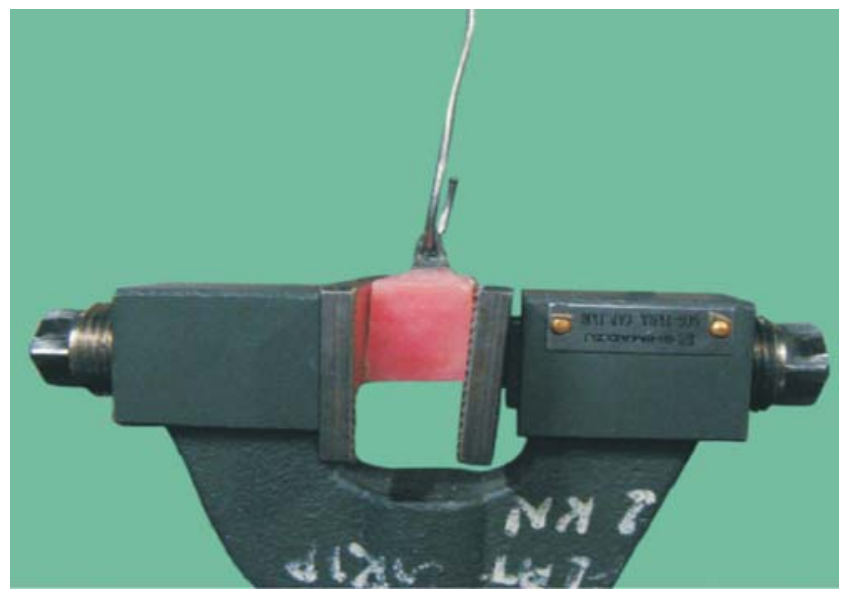

Figure 4

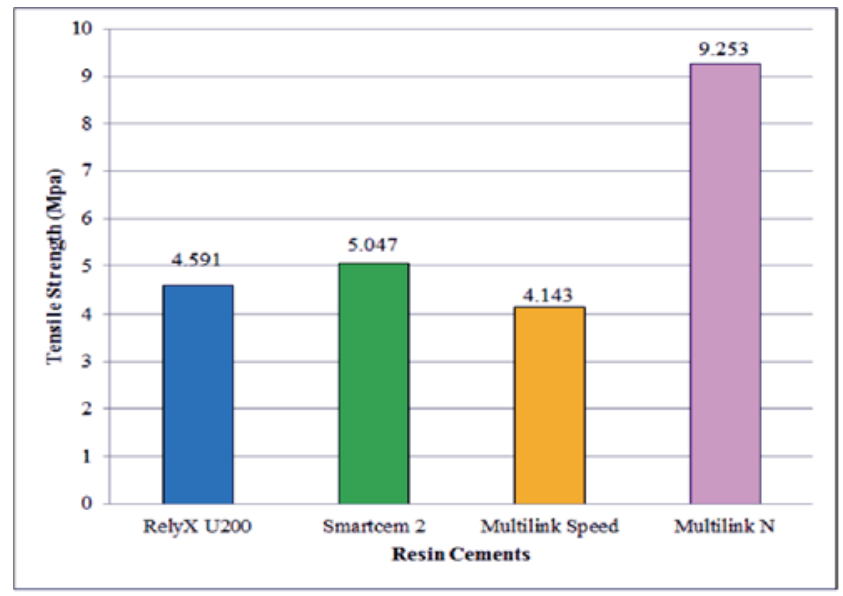

Figure 5

$\left(1 \mathrm{MPa}=1 \mathrm{~N} / \mathrm{mm}^{2}\right)$ was calculated. ANOVA (one way analysis of variance) and POST-HOC tests were used for statistical analysis.

\section{RESULTS}

The means of tensile bond strength (MPa) values of all the four groups was tested (Table 1). Multilink $\mathrm{N}$ showed the maximum mean tensile bond strength followed by Smartcem 2 and RelyX U200.

Lowest mean tensile bond strength was exhibited by Multilink Speed among all the tested cements (Fig 5). One way ANOVA (Table 2) showed a highly statistically significant $(p<0.01)$ difference between all the four resin cements i.e RelyX U200, Smartcem2, Multilink Speed and Multilink N.
Post Hoc Tests- Multiple comparisons (Table 3) showed highly statistically significant $(p<0.01)$ difference between RelyX U200: Multilink N, Smartcem 2: Multilink Speed, Smartcem 2: Multilink N, Multilink Speed: Multilink N. Difference between RelyX U200 : Smartcem 2 and RelyX U200 : Multilink Speed was statistically significant $(\mathrm{p}<0.05)$.

\section{DISCUSSION}

New cements are introduced in the market every day. Recently, newly developed resin luting cements along with "self-adhesive luting cements" have been commercialized from several manufacturers. Many claim superiority in rate of setting, working and handling characteristics, strength etc. Of these the claims of superior retentive strength has more significance in its contribution to fixed prosthesis. The tensile bond strength determines the adhesive and the retentive ability of the luting agent. ${ }^{4}$ Thus, the tensile pull off test was used in the present study to analyse the bond strength. To get meaningful results the most influencing factors had to be controlled. ${ }^{5}$ The present study used freshly extracted natural central incisors which were flattened and thus standardized to obtain ideal tooth preparation geometry and to avoid variations in the study. The bond strength of adhesive luting cements to enamel and dentin varies. $^{6}$ To avoid this surface variation the tooth reduction was ended on enamel for all the samples in which teeth were flattened in such a way to ensure that enamel was continuous and dentin was not exposed.

Bond strength to enamel and dentin higher than 20MPa may be adequate to resist stress generated by polymerization shrinkage. ${ }^{7}$ However, there is a large range of variation ( 7 to $40 \mathrm{MPa}$ ) in relation to bonding of different dentin bonding agents or resin luting agents for both substrates. ${ }^{8}$ Comparisons among different studies are complicated because of the different approaches used to test adhesive ability. Multilink N resin Cement showed the maximum bond strength among all adhesive luting cements (Mean bond strength of $9 \mathrm{MPa}$ ). These results are in accordance with study done by Abo $\mathrm{T}$ et $\mathrm{al}^{9}$ in which self-etch luting cement showed higher micro tensile bond strength as compared to three self-adhesive luting cements used in 
their study. Multilink $\mathrm{N}$ is composed of dimethacrylate and HEMA. The inorganic fillers are barium glass, ytterbium trifluoride, spheroid mixed oxide. The total volume of inorganic fillers is approximately $40 \%$. This high bond strength of Multilink $\mathrm{N}$ resin Cement is attributed to surface pretreatment of tooth and restoration. However, other three resin cements used in the present study claim that the adhesion is possibly achieved to various surfaces without surface pretreatment. Self-etching and self-curing primer (Multilink N Primer A/B) contains an aqueous solution of HEMA (2-hydroxyethyl methacrylate), phosphoric acid and acrylic acid monomers. Metal primer contains phosphoric acid methacrylate and methacrylate crosslinking agent in an organic solvent, which act as a bonding agent and create durable chemical bond between luting composite and metal restoration. This is in accordance with study by Abreu A et $\mathrm{al}^{10}$ that metal primer application significantly enhanced tensile bond strength to base metal alloy.

The adhesion of self-adhesive cement to ground enamel was assessed in several studies that evaluated bond strength and cement enamel interface micromorphology. ${ }^{11,12}$ In present study all 3-selfadhesive luting cements showed less bond strength than self-etch resin cement. Moraes RR et al suggested that self-adhesive resin cements present slower polymerization and lower degree of conversion than conventional resin cements, in either the dual or selfcure mode. ${ }^{13}$

Smartcem 2 resin cement contains resins that provide structural reinforcement of the cement and that also offer strong cross-link bonding following polymerization. It is based on Primer and Bond chemistry, containing the phosphoric acid modified monomer PENTA, which has been shown to bond chemically as well as mechanically by interacting chemically with the calcium contained in the tooth structure. $^{14}$

Simon JF et $\mathrm{al}^{15}$ measured the bond strength of the self-adhesive resin cements (SmartCem 2, Rely X Unicem and 3 more self-adhesive cements) and new self-etching resin cement (Multilink) for crowns bonded to extracted teeth with preparations having a total taper greater than 30 degrees and concluded that some of the new self-etching resin cements can create bonds to non-retentive crown preparations that are stronger. Capa $\mathrm{N}$ et $\mathrm{al}^{16}$ evaluate the influence of $\mathrm{Er}$ :YAG laser irradiation on shear-bond strength of 3 selfadhesive resin cements- SmartCem 2, RelyX Unicem, Multilink Automix. The highest bond-strength value was obtained with SmartCem 2.

RelyX U200 contains bifunctional methacrylate. Bond strength of RelyX Unicem was investigated using micro-tensile bond strength tests. Enamel micro-tensile bond strengths of RelyX Unicem ranged between 10.7 $\mathrm{MPa}$ and 19.6 MPa and were significantly lower than the bond strengths of the self-etching cement. RelyX Unicem microtensile bond strength to enamel was comparable to other resin cements when its application was preceded by phosphoric acid etching. Morphological evaluations revealed that Rely X Unicem should be applied using some pressure in order to ensure its close adaptation to the cavity wall. However, pressure twice as high as finger pressure had no effect on the micro-tensile bond strength of RelyX Unicem and other investigated cements to flat ground enamel surfaces .

Multilink speed is composed of dimethacrylates and acidic monomers. The inorganic fillers are barium glass, yttrium trifluoride, co polymer and highly dispersed silicon dioxide, catalysts, stabilizers and color pigments.

Among self- adhesive cements, the cement with low $\mathrm{pH}$ value might have an etching effect but an adverse influence on the adhesion if the low $\mathrm{pH}$ were left too long. Several self-etch cements tend to show high initial acidity and gradual rise of $\mathrm{pH}$ during setting. ${ }^{17}$

In present study, Smartcem 2 showed relatively higher bond strength than RelyX U200 and RelyX U200 shows slightly higher bond strength than Multilink speed. These differences may be due to the etching effect by the different $\mathrm{pH}$ and different chemical composition. Thus multilink speed might be having high initial $\mathrm{pH}$ followed by RelyX U200 and Smartcem 2 . 
Morphological evaluations shows higher failure frequencies at enamel/cement interface than cohesively within the cement for all the four cements evaluated. The low bond strengths recorded for the self-adhesive cements are probably related to the cements' limited ability to demineralize and infiltrate tooth substrate. ${ }^{18,19}$ Despite their initial low $\mathrm{pH}$, the higher viscosity of the self-adhesive cements, if compared to self-etching primers, may explain why no true hybrid layer is formed. These cements should be able to etch the substrate in a relatively short time, requiring optimal wetting properties to ensure a fast interaction with enamel. Despite the shorter working time, luting of a less retentive preparation by use of self-adhesive cements should be avoided with these systems. The bonding ability of self-adhesive cements can be attributed, in part or primarily; to their ability to chemically interact with hydroxyapatite. ${ }^{20,21}$ This observation can explain the high number of adhesive failures for the self-adhesive materials. Therefore, further studies evaluating longevity of resin bonds created in dental treatment, effect of various surface treatments for tooth and restoration surface, bond strength to dentin and ultra-morphological features of bonding interfaces created by such newly available products are required.

The Clinical implication of this study is the greatest advantage of self-adhesive cements is the easy and fast application technique. But this time saving technique is not as effective as self- etch resin luting agents. The presumed benefit of saving time with self-adhesive luting agents may only be realized at the expense of compromising bond strength.

\section{CONCLUSION}

Based on the observations and results of this study following conclusions were made:

1. Self- etch resin cement (Multilink N) showed maximum mean tensile bond strength as compared to self- adhesive resin cements (Smartcem 2, RelyX U200 and Multilink Speed).

2. Ni-Cr cast alloy cemented to tooth enamel using Multilink N Resin Cement showed the maximum mean tensile bond strength followed by Smartcem 2, RelyX U200 and Multilink Speed among all the four adhesive luting cements tested.

\section{REFERENCES}

1. Radovic I, Monticelli F, Goracci C, Vulicevic ZR, Ferrarie M. Self-adhesive Resin Cements: A Literature Review. J Adhes Dent. 2008; 10(4):251-8.

2. De Munck J, Vargas M, Van Landuyt K, Hikita K, Lambrechts P, Van Meerbeek B. Bonding of an auto-adhesive luting material to enamel and dentin. Dent Mater. 2004; 20(10):96371.

3. Abo-Hamar SE, Hiller KA, Jung H, Federlin M, Friedl KH, Schmalz G. Bond strength of a new universal self-adhesive resin luting cement to dentin and enamel. Clin Oral Investig. 2005; 9(3):161-7.

4. Mitchella CA, Abbarikia M, Orrb JF. The influence of luting cement on the probabilities of survival and modes of failure of cast full coverage crowns. Dent Mater. 2000; 16(3):198-206.

5. Heintz SD. Crown pull-off test (crown retention) to evaluate the bonding effectiveness of luting agents. Dent Mater. 2010; 26(3):193-206.

6. Abate PF, Bertacchini SM, Polack MA, Macchi RL. Adhesion of compomer to dental Structures. Quintessence Int. 1997; 28(8):509-12.

7. Eick JD, Gwinnett AJ, Pashley DH, Robinson SL. Current concepts on adhesion to dentin. Crit Rev Oral Biol Med. 1997; 8(3):306-35.

8. Kitasako Y, Burrow MF, Katahira N, Nikaido T, Tagami J. Shear bond strengths of three resin cements to dentine over 3 years in vitro. J Dent. 2001; 29(2):139-44.

9. Abo T, Uno S, Yoshiyama M, Yamada T, Hanada N. Microtensile Bond Strength of Self-Adhesive Luting Cements to Ceramics. Int J Dent. 2012;107(2):109-18.

10. Abreu A, Loza MA, Elias A, Mukhopadhyay S, Looney S, Rueggeberg FA. Tensile bond strength of an adhesive resin cement to different alloys having various surface treatments. J Prosthet Dent. 2009; 101(2):107-18.

11. Goracci C, Cury AH, Cantoro A, Papacchini F, Tay FR, Ferrari M. Microtensile bond strength and interfacial properties of self-etching and self-adhesive resin cements used to lute composite onlays under different seating forces. J Adhes Dent. 2006; 8(5):327-35.

12. Hikita K, Van Meerbeek B, De Munck J, Ikeda T, Van Landuyt K, Maida T, Lambrechts P, Peumans M. Bonding effectiveness 
of adhesive luting agents to enamel and dentin. Dent Mater. 2007; 23(1):71-80.

13. Moraes RR, Boscato N, Jardim PS, Schneider LFJ. Dual and Self-curing Potential of Self-adhesive Resin Cements as Thin Films. Oper Dent. 2011;36(6):635-42.

14. Latta MA. Shear bond strength and physicochemical interactions of XP BOND. JAdhes Dent. 2007;9(2):245-8.

15. Simon JF, De Rijk WG, Hill J, Hill N. Tensile bond strength of ceramic crowns to dentin using resin cements. Int J Comput Dent. 2011; 14(4):309-19.

16. Capa N, Aykor A, Ozel E, Calikkocaoglu S, Soyman M. Effect of Er:YAG laser irradiations on shear bond strength of three self-adhesive resin cements to dentin. Photomed Laser Surg. 2010;28(6):809-21.

17. Saskalauskaite E, Tam LE, McComb D. Flexural strength, elastic modulus, and $\mathrm{pH}$ profile of self-etch resin luting cements. J Prosthodont. 2008; 17(4):262-8.
18. Goracci C, Sadek FT, Fabianelli A, Tay FR, Ferrari M. Evaluation of the adhesion of fiber posts to intraradicular dentin. Oper Dent. 2005; 30(5):627-35.

19. Monticelli F, Osorio R, Mazzitelli C, Ferrari M, Toledano M. Limited decalcification/diffusion of self-adhesive cements into dentin. J Dent Res. 2008; 87(10):974-9.

20. Yoshida Y, Nagakane K, Fukuda R, Nakayama Y, Okazaki M, Shintani H, Inoue S, Tagawa Y, Suzuki K, De Munck J, Van Meerbeek B. Comparative study on adhesive performance of functional monomers. J Dent Res. 2004; 83(6):454-8.

21. Gerth HU, Dammaschke T, Züchner H, Schäfer E. Chemical analysis and bonding reaction of RelyX Unicem and Bifix composites-a comparative study. Dent Mater. 2006; 22(10):934-41. 